\title{
Early Detection of Alzheimer's Disease with PET Imaging
}

\author{
V. Berti ${ }^{a}$ d $\quad$ R.S. Osorio ${ }^{a, b} \quad$ L. Mosconi ${ }^{a} \quad$ Y. Li $i^{a} \quad$ S. De Santi ${ }^{a} \quad$ M.J. de Leon ${ }^{a, c}$ \\ ${ }^{a}$ Department of Psychiatry, Center for Brain Health, ${ }^{b}$ Departments of Pathology and Psychiatry, Alzheimer's Disease \\ Center, New York University School of Medicine, New York, N.Y., and ' Nathan Kline Institute, Orangeburg, N.Y., USA; \\ ${ }^{\mathrm{d}}$ Nuclear Medicine Unit, Clinical Pathophysiology Department, University of Florence, Florence, Italy
}

\section{Key Words}

Alzheimer's disease biomarkers • PET neuroimaging •

Early diagnostic tools $\cdot$ Amyloid lesions

\begin{abstract}
Preclinical diagnosis of Alzheimer's disease (AD) is one of the major challenges for the prevention of AD. AD biomarkers are needed not only to reveal preclinical pathologic changes, but also to monitor progression and therapeutics. PET neuroimaging can reliably assess aspects of the molecular biology and neuropathology of AD. The aim of this article is to review the use of FDG-PET and amyloid PET imaging in the early detection of AD.

Copyright $\odot 2010$ S. Karger AG, Base
\end{abstract}

\section{Introduction}

Alzheimer's disease (AD) is the most common form of dementia and is characterized by progressive impairments in cognitive function and behavior [1]. The provisional diagnosis of $\mathrm{AD}$ is based on clinical history, neurological/psychiatric examinations, cognitive testing and neuroimaging, while a definitive diagnosis requires the postmortem observation of specific pathological lesions: intracellular neurofibrillary tangles (NFT), amyloid- $\beta$ $(\mathrm{A} \beta)$ plaques, synapse/neuronal loss and atrophy [2].

Some of these lesions begin to form 20-30 years before the disease becomes clinically evident [3], indicating the possibility for developing early and sensitive biomarkers of the disease. As a matter of fact, the need for biomarkers in $\mathrm{AD}$ is real, in particular to reveal preclinical pathological alterations, to monitor objectively and accurately disease progression, and eventually to evaluate the response to therapy [4].

Several neuroimaging modalities show promising results as early diagnostic tools for AD. These include MRI for structural assessment, and PET imaging for both glucose metabolism and for $A \beta$ and possibly NFT binding.

MRI imaging plays an important and routine role in the differential diagnosis of AD from some other dementias (vascular dementia) [5]. Several studies have shown that medial temporal lobes (MTL) atrophy is an early sign of $\mathrm{AD}$ and predicts conversion to dementia in normal subjects [5]. However, functional imaging, especially 2$\left[{ }^{18} \mathrm{~F}\right]$ fluoro-2-deoxy-D-glucose (FDG) PET, has played the leading role in the early detection of AD. FDG-PET provides qualitative and quantitative estimates of the cerebral metabolic rate of glucose (CMRglc), an index of synaptic functioning and density $[6,7]$. The major limitation of this highly sensitive modality (FDG-PET sensitivity in

\section{KARGER}

Fax +41613061234 E-Mail karger@karger.ch www.karger.com
(C) 2010 S. Karger AG, Base

$1660-2854 / 10 / 0073-0131 \$ 26.00 / 0$

Accessible online at:

www.karger.com/ndd
Prof. Mony de Leon

Center for Brain Health, Department of Psychiatry, NYU School of Medicine 550 First Avenue

New York, NY 10016 (USA)

E-Mail mony.deleon@nyumc.org 
Table 1. CMRglc reductions in $\mathrm{AD}$ and 'high-risk' populations compared to normal controls

\begin{tabular}{|c|c|c|}
\hline Population & CMRglc findings & $\begin{array}{l}\text { Percentage reduction } \\
\text { vs. controls }\end{array}$ \\
\hline AD patients & $\begin{array}{l}\text { Regional CMRglc reductions in MTL, PTC, } \\
\text { PCC and FC, and WB hypometabolism [9, 13-16] }\end{array}$ & $\begin{array}{ll}\text { WB: } & 28-29 \% \\
\text { MTL: } & 20-30 \% \\
\text { PCC: } & 18-22 \% \\
\text { PC: } & 15-40 \% \\
\text { FC: } & 22-24 \%\end{array}$ \\
\hline Asymptomatic FAD mutations carriers & Hypometabolism in MTL, PTC, PCC and FC [17] & $\begin{array}{l}\text { MTL: } 12 \% \\
\text { PCC: } 21 \%\end{array}$ \\
\hline Asymptomatic ApoE4 carriers & $\begin{array}{l}\text { Hypometabolism in MTL, PTC, PCC and FC, } \\
\text { occipital cortex, and thalamus }[18,19]\end{array}$ & $\begin{array}{ll}\text { PCC: } & 10.5 \% \\
\text { PTC: } & 10 \% \\
\text { FC: } & 9.8 \%\end{array}$ \\
\hline $\begin{array}{l}\text { Asymptomatic patients with a } \\
\text { maternal family history of AD }\end{array}$ & $\begin{array}{l}\text { Hypometabolism in MTL, PCC/precuneus, } \\
\text { IP and FC [21] }\end{array}$ & $\begin{array}{ll}\text { MTL: } & 15 \% \\
\text { PCC: } & 22 \% \\
\text { IP: } & 12 \% \\
\text { FC: } & 10 \%\end{array}$ \\
\hline MCI & $\begin{array}{l}\text { Hypometabolism in MTL, PCC and PTC in amnestic MCI [20] } \\
\text { Nonamnestic MCI show either absence of cortical hypometabolism } \\
\text { or CMRglc reductions in ACC and PTC }[20,22]\end{array}$ & $\begin{array}{ll}\text { MTL: } & 8.6 \% \\
\text { IP: } & 8.9 \%\end{array}$ \\
\hline SMC & $\begin{array}{l}\text { Hypometabolism in the PHG, PTC, inferior frontal cortex } \\
\text { and thalamus [19] }\end{array}$ & $\begin{array}{l}\text { PHG: } 18 \% \\
\text { PTC: } 16 \%\end{array}$ \\
\hline
\end{tabular}

$\mathrm{ACC}=$ Anterior cingulate cortex; $\mathrm{PC}=$ parietal cortex; $\mathrm{IP}=$ inferior parietal lobe; $\mathrm{PHG}=$ parahippocampal gyrus; $\mathrm{WB}=$ whole brain.

histopathologically confirmed $\mathrm{AD}$ is $94 \%$ ) [8] is its lack of disease specificity (73\%), as reductions in CMRglc are often found in other dementias [9]. A new and effective strategy is to use amyloid PET radiotracers to target the amyloid lesions of AD [10,11]. This approach increases specificity and improves diagnostic accuracy, particularly if combined with FDG [12].

\section{FDG-PET Imaging}

FDG-PET studies in AD demonstrate consistent and progressive CMRglc reductions, whose extent and topography correlate with symptom type and severity [13]. Virtually all FDG-PET studies report that, compared to agematched healthy normal controls, AD patients show both widespread global metabolic impairment and regional metabolic reductions involving MTL, parietotemporal (PTC) and posterior cingulate cortices (PCC) [9, 13-15] (table 1). The frontal cortex (FC) is also involved in more advanced AD stages $[9,16]$. This pattern is seen in con- trast to relative preservation of primary motor/visual areas, cerebellum, thalamus and basal ganglia (fig. 1).

Importantly, CMRglc reductions have been observed with FDG-PET before the onset of AD symptoms, highlighting the importance of PET as a tool for early detection and estimation of increased risk for future dementia.

So far, research in the early diagnosis of $\mathrm{AD}$ has focused on individuals from 'high-risk' populations who are more likely to develop the disease as compared to 'low-risk' subjects. These 'high-risk' populations include carriers of any of the autosomal dominant mutations for early-onset familial AD (FAD) [17], carriers of an apolipoprotein E4 (ApoE4) allele [18, 19], individuals with subjective memory complaints (SMC) or mild cognitive impairment (MCI) $[9,19,20]$, and individuals with a family history of $\mathrm{AD}$, particularly when the mothers are affected [21].

Most of the studies show AD-like CMRglc reductions in these at-risk groups, intermediate between controls and $\mathrm{AD}$ patients, years prior to clinical decline (table 1). 

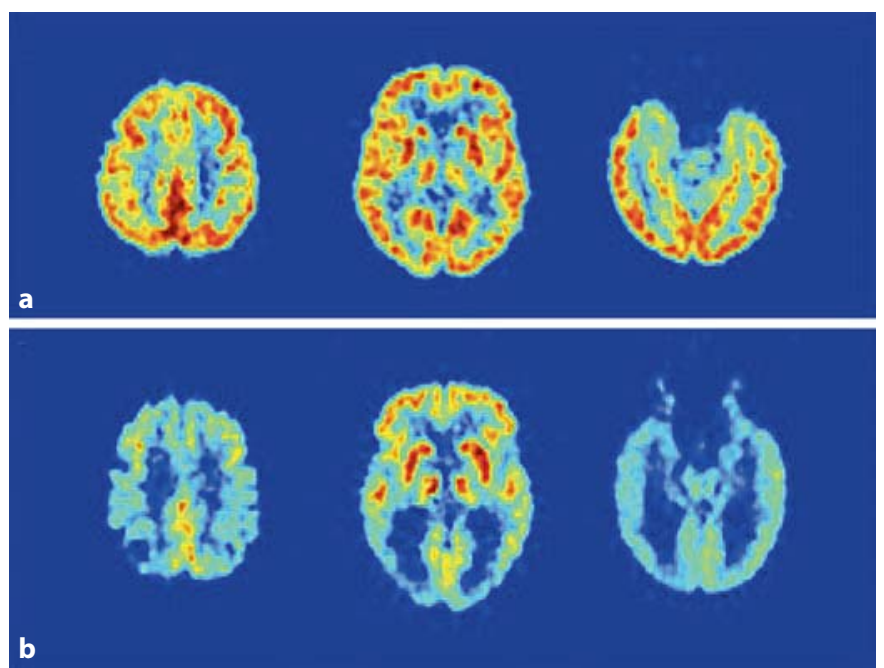

Fig. 1. FDG-PET scans from two representative subjects: normal subject (a) and $\mathrm{AD}$ subject (b). PET scans are displayed in the axial plane, from the top to the bottom of the brain, at the level of the centrum-semiovale (left), basal ganglia (center), and MTL (right). Note the hypometabolism involving parietotemporal regions, posterior cingulate/precuneus, medial temporal cortex, and to a lesser extent $\mathrm{FC}$ in the $\mathrm{AD}$ patient as compared to the normal subject.



Fig. 2. FDG-PET scan from a representative MCI subject. PET scan is displayed in the axial plane, from the top to the bottom of the brain, at the level of the centrum-semiovale (left), basal ganglia (center), and MTL (right). Note the moderate hypometabolism involving posterior cingulate/precuneus, parietal and medial temporal cortices.

For example, MCI conversion studies report a predictive pattern of CMRglc reductions involving the regions typically hypometabolic in AD, such as MTL, PCC and PTC. These patterns are not present in 'stable' MCI (fig. 2) [20, 22]. Likewise, in cognitively normal subjects, a pattern of MTL hypometabolism with subsequent cortical reductions was demonstrated to precede and predict decline to
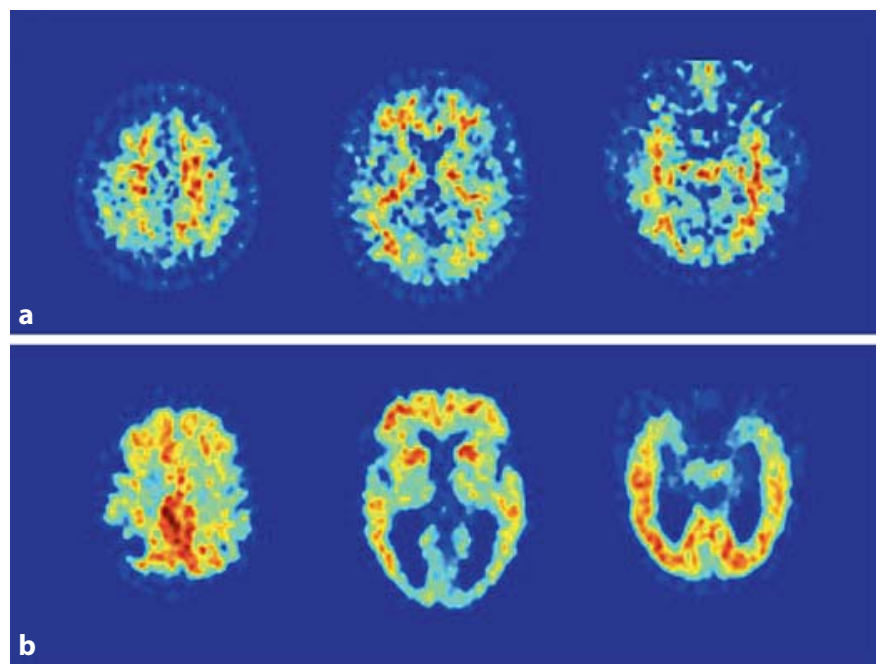

Fig. 3. PIB-PET scans from two representative subjects: normal subject (a) and AD subject (b). PET scans are displayed in the axial plane, from the top to the bottom of the brain, at the level of the centrum-semiovale (left), basal ganglia (center), and MTL (right). Note that in the normal subject PIB is distributed only in the white matter, reflecting nonspecific uptake, and in the $\mathrm{AD}$ patient PIB uptake is present in several cortical regions, such as frontal, parietal, posterior cingulate/precuneus and lateral temporal cortices, and in basal ganglia.

$\mathrm{MCI}$ and postmortem verified $\mathrm{AD}[23,24]$. However, $\mathrm{CMRglc}$ reductions are less effective in predicting decline in SMC and nonamnestic MCI, two subtypes whose outcome appears to be more heterogeneous, reflecting other dementia and psychiatric disorders $[19,22]$.

\section{Amyloid PET Imaging}

The development of amyloid imaging ligands has greatly advanced our understanding of the pathophysiology of AD. Among A $\beta$ PET tracers, the best known is Nmethyl- $\left[{ }^{11} \mathrm{C}\right]-2-\left(4^{0}\right.$-methylaminophenyl)-6-hydroxybenzothiazole, also known as Pittsburgh Compound-B (PIB) [10]. PIB-PET studies demonstrate significant PIB retention in $\mathrm{AD}$ patients as compared to controls, mostly evident in the middle and prefrontal cortex, PTC, PCC/precuneus, occipital lobes, thalamus and striatum [10, 25] (fig. 3). About $50 \%$ of amnestic MCI patients are PIB positive, and PIB retention is found also in as many as $22 \%$ of normal elderly [26]. These findings, when considered together with pathology reports that PIB may not be specific for dense classical $A \beta$ plaques [27], suggest that PIBPET may be difficult to interpret in nonsymptomatic subjects. 
Table 2. PIB-PET imaging studies in $\mathrm{AD}$ and 'high-risk' populations compared to normal controls

\begin{tabular}{lll}
\hline Risk factor & PIB-PET findings & $\begin{array}{l}\text { PIB uptake } \\
\text { values }\end{array}$ \\
\hline \multirow{2}{*}{ AD patients } & $\begin{array}{l}\text { Increased PIB uptake in middle } \\
\text { and lateral FC, PC, LTC, }\end{array}$ & FC: 1.8 \\
& PCC/precuneus, OC, thalamus & LTC: 1.7 \\
& and striatum [10, 25] & PCC: 1.9 \\
& & OC: 1.7 \\
\hline FAD muta- & Increased PIB uptake in & Striatum: 1.6 \\
tion carriers & striatum, FC, LTC [28] & Striatum: 2.0 \\
& & FC: 1.6 \\
\hline ApoE4 & Increased PIB uptake in FC, 1.4 \\
& PCC/precuneus, LTC, PC, & FC: 1.4 \\
& basal ganglia [29] & PCC: 1.5 \\
& & LTC: 1.4 \\
& & PC: 1.4 \\
& & Striatum: 1.4 \\
\hline MCI & uptake in FC, ACC, IP, & In the PIB- \\
& PCC/precuneus [30]; & positive group: \\
& 46\% with PIB uptake in the & ACC: 1.6 \\
& normal range [30] & IP: 1.6 \\
& & PCC: 1.8 \\
\hline
\end{tabular}

PIB uptake values: cerebral-to-cerebellar PIB standardized uptake ratios.

LTC $=$ Lateral temporal cortex; OC $=$ occipital cortex. from the combination of the two modalities with the accuracy raised to $90 \%$ in the identification of MCI patients, suggesting that PIB alone may not be sufficient in the determination of risk among at-risk subjects, and a combination with a complementary modality, such ad FDG-PET, is necessary. Longitudinal studies are needed to assess whether risk of decline is higher in MCI patients with both fibrillar amyloid deposits and CMRglc reductions, compared to either deficit alone.

Another amyloid PET imaging tracer, 2-(1-96-(2${ }^{18}$ F-fluoroethyl)(methyl)amino)2-naphthyl)ethyldene) malononitrile ( ${ }^{18} \mathrm{~F}$-FDDNP) has been studied to a lesser extent in AD. FDDNP is a fluorinated radiotracer that binds with high specificity to both $A \beta$ fibrils and NFTs [11]. ${ }^{18} \mathrm{~F}$-FDDNP binding was elevated in AD and MCI patients as compared with healthy elderly, and showed uptake in the MTL, yielding 100\% diagnostic separation between $\mathrm{AD}$ and controls, and 95\% between MCI and controls [11].

The capacity of ${ }^{18} \mathrm{~F}$-FDDNP to bind to NFT in addition to $A \beta$ could be a potential early diagnostic advantage as it may reveal early NFT pathology [31]. It is known that NFT pathology appears in the MTL in early stages of AD [3], and an increased NFT load is highly correlated with memory impairment, while amyloid deposits are not [32]. However, further studies are needed to assess the extent to which ${ }^{18} \mathrm{~F}$-FDDNP helps establish early diagnosis and increase diagnostic specificity. Limitations regarding this tracer have been published [32].

\section{Conclusion}

The search for sensitive and specific biomarkers for AD has been a challenge. Several FDG-PET studies have shown that hypometabolism in the MTL and cortical areas could be useful as an imaging biomarker for asymptomatic 'high-risk' populations. There remains a great need to increase the preclinical diagnostic accuracy, and the combination of FDG-PET with amyloid PET imaging has proven an effective strategy in the identification of $\mathrm{AD}$ and MCI. Future studies targeting normal elderly with various risk factors for $\mathrm{AD}$ are warranted.

\section{Acknowledgement}

Supported by a grant from the Alzheimer's Disease Research Unit CIEN Foundation - Reina Sofia Foundation, Madrid, Spain. 


\section{References}

$\checkmark 1$ Cummings JL: Toward a molecular neuropsychiatry of neurodegenerative diseases. Ann Neurol 2003;54:147-154.

\2 Mirra SS, Heyman A, McKeel D, Sumi SM, Crain BJ, Brownlee LM, et al: The consortium to establish a registry for Alzheimer's disease (CERAD). II. Standardization of the neuropathologic assessment of Alzheimer's disease. Neurology 1991;41:479-486.

$\checkmark 3$ Braak H, Braak E: Neuropathological stageing of Alzheimer related changes. Acta Neuropathologica 1991;82:239-259.

$\checkmark 4$ Berg D: Biomarkers for the early detection of Parkinson's and Alzheimer's disease. Neurodegener Dis 2008;5:133-136.

$\checkmark 5$ Rusinek H, De Santi S, Frid D, Tsui W, Tarshish C, Convit A, et al: Regional brain atrophy rate predicts future cognitive decline: 6 -year longitudinal MR imaging study of normal aging. Radiology 2003;229:691-696.

$\checkmark 6$ Rocher AB, Chapon F, Blaizot X, Baron JC, Chavoix C: Resting-state brain glucose utilization as measured by PET is directly related to regional synaptophysin levels: a study in baboons. Neuroimage 2004;20:1894-1898.

7 Pellerin L, Magistretti PJ: Glutamate uptake into astrocytes stimulates aerobic glycolysis: a mechanism coupling neuronal activity to glucose utilization. PNAS 1994;91:1062510629.

$>_{8}$ Silverman DH, Small GW, Chang CY, Lu CS, Kung De Aburto MA, Chen W, et al: Positron emission tomography in evaluation of dementia: regional brain metabolism and longterm outcome. JAMA 2001;286:2120-2127.

$\checkmark 9$ Mosconi L, Tsui WH, Herholz K, Pupi A, Drzezga A, Lucignani G, et al: Multicenter standardized 18F-FDG PET diagnosis of mild cognitive impairment, Alzheimer's disease, and other dementias. J Nucl Med 2008; 49:390-398.

-10 Klunk WE, Engler H, Nordberg A, Yanming W, Blomqvist G, Holt DP, et al: Imaging brain amyloid in Alzheimer's disease with Pittsburgh Compound-B. Ann Neurol 2004; 55:306-319.

-11 Small GW, Kepe V, Ercoli LM, Siddarth P, Bookheimer SY, Miller KJ, et al: PET of brain amyloid and tau in mild cognitive impairment. N Engl J Med 2006;355:2652-2663.
12 Li Y, Rinne JO, Mosconi L, Pirraglia E, Rusinek H, DeSanti S: Regional analysis of FDG and PIB-PET images in normal aging, mild cognitive impairment, and Alzheimer's disease. Eur J Nucl Med Mol Imaging 2008; 35:2169-2181.

13 Mosconi L: Brain glucose metabolism in the early and specific diagnosis of Alzheimer's disease. Eur J Nucl Med 2005;32:486-510.

14 Mosconi L, De Santi S, Li Y, Li J, Zhan J, Tsui $\mathrm{WH}$, et al: Visual rating of medial temporal lobe metabolism in mild cognitive impairment and Alzheimer's disease using FDGPET. Eur J Nucl Med 2006;33:210-221.

$\checkmark 15$ Minoshima S, Giordani B, Berent S, Frey KA, Foster NL, Kuhl DE: Metabolic reduction in the posterior cingulate cortex in very early Alzheimer's disease. Ann Neurol 1997;42: 85-94.

-16 Foster NL, Chase TN, Mansi L, Brooks R, Fedio P, Patronas NJ, et al: Cortical abnormalities in Alzheimer's disease. Ann Neurol 1984;16:649-654.

17 Mosconi L, Sorbi S, de Leon MJ, Li Y, Nacmias B, Bessi V, et al: Hypometabolism exceeds atrophy in presymptomatic early-onset familial Alzheimer's disease. J Nucl Med 2006:47:1778-1786.

18 Reiman EM, Chen K, Alexander GE, Caselli RJ, Bandy D, Osborne D, et al: Functional brain abnormalities in young adults at genetic risk for late-onset Alzheimer's dementia. PNAS 2004;101:284-289.

19 Mosconi L, De Santi S, Brys M, Tsui WH, Pirraglia E, Glodzik-Sobanska L, et al: Hypometabolism and altered cerebrospinal fluid markers in normal apolipoprotein E E4 carriers with subjective memory complaints. Biol Psychiatry 2008 15;63:609-618.

20 Drzezga A, Lautenschlager N, Siebner H, Riemenschneider M, Willoch F, Minoshima $S$, et al: Cerebral metabolic changes accompanying conversion of mild cognitive impairment into Alzheimer's disease: a PET follow-up study. Eur J Nucl Med 2003;30: 1104-1113.

21 Mosconi L, Brys M, Switalski R, Mistur R, Glodzik-Sobanska L, Pirraglia E, et al: Maternal family history of Alzheimer's disease predisposes to reduced brain glucose metabolism. PNAS 2007;104:19067-19072.

$\checkmark 22$ Anchisi D, Borroni B, Franceschi M, Kerrouche N, Kalbe E, Beuthien-Beumann B, et al: Heterogeneity of brain glucose metabolism in mild cognitive impairment and clinical progression to Alzheimer disease. Arch Neurol 2005;62:1728-1733.
23 de Leon MJ, Convit A, WolfOT, Tarshish CY, DeSanti S, Rusinek $\mathrm{H}$, et al: Prediction of cognitive decline in normal elderly subjects with 2-[(18)F]fluoro-2-deoxy-D-glucose/ positron-emission tomography (FDG/PET). PNAS 2001;98:10966-10971.

24 Mosconi L, Mistur R, Switalski R, Tsui WH, Glodzik L, Li Y, et al: FDG-PET changes in brain glucose metabolism from normal cognition to pathologically verified Alzheimer's disease. Eur J Nucl Med Mol Imaging 2009; 36:811-822.

25 Kemppainen N, Aalto S, Wilson I, Nagren K, Helin S, Bruck A, et al: Voxel-based analysis of PET amyloid ligand [11C]PIB uptake in Alzheimer disease. Neurology 2006;67: 1575-1580.

26 Mintun MAM, LaRossa GN, Sheline YIM, Dence CSM, Lee SYP, Mach RHP, et al: [11C]PIB in a nondemented population: potential antecedent marker of Alzheimer disease. Neurology 2006;67:446-452.

$\checkmark 27$ Lockhart A, Lamb JR, Osredkar T, et al: PIB is a non-specific imaging marker of amyloidbeta $(A \beta)$ peptide-related cerebral amyloidosis. Brain 2007;130:2607-2615.

28 Klunk WE, Price JC, Mathis CA, Tsopelas ND, Lopresti BJ, Ziolko SK, et al: Amyloid deposition begins in the striatum of presenilin-1 mutation carriers from two unrelated pedigrees. J Neurosci 2007;27:6174-6184.

29 Reiman EM, Chen K, Liu X, Bandy D, Yu M, Lee W, et al: Fibrillar amyloid-beta burden in cognitively normal people at 3 levels of genetic risk for Alzheimer's disease. PNAS 2009; 106:6820-6825

-30 Wolk DA, Price JC, Saxton JA, Snitz BE, James JA, Lopez OL, et al: Amyloid imaging in mild cognitive impairment subtypes. Ann Neurol 2009;65:557-568

31 de Leon MJ, Mosconi L, Logan J: Seeing what Alzheimer saw. Nat Med 2007;13:129-131.

32 Powell MR, Smith GE, Knopman DS, Parisi JE, Boeve BF, Petersen RC, et al: Cognitive measures predict pathologic Alzheimer disease. Arch Neurol 2006;63:865-868. 